\title{
A COMPREENSÃO DE TEMAS DAS CIÊNCIAS SOCIAIS POR MEIO DA PESQUISA QUALITATIVA
}

\section{UNDERSTANDING SOCIAL SCIENCES THEMES THROUGH QUALITATIVE RESEARCH}

\section{Elisete Martins Ferreira ${ }^{1}$, Carolina Lopes Araújo² e Lucimara Fabiana Fornari ${ }^{3}$}

1 ISLA - IPGT, Escola de Gestão, Portugal, e-mail: elisete.martins@islagaia.pt

2 Universidade de Brasília, Faculdade UnB Planaltina, Brasil, e-mail: carolinalopesaraujo@yahoo.com.br

3 Universidade de São Paulo, Departamento de Enfermagem em Saúde Coletiva, Brasil, e-mail: lucimarafornari@usp.br

ART I C LE I N F O

Article history:

Received 2020-01-15

Accepted 2020-04-10

Available online 2020-04-10
Palavras-chave: Pesquisa qualitativa. Ciências sociais Interdisciplinar.

Keywords: Qualitative research. Social sciences. Interdisciplinary.

"Ainda que a relação de pesquisa se distinga da maioria das trocas da existência comum, já que tem por fim o mero conhecimento, ela continua, apesar de tudo, uma relação social que exerce efeitos (variáveis segundo os diferentes parâmetros que a podem afetar) sobre os resultados obtidos"

(BOURDIEU, 1997, p. 694)

A pesquisa qualitativa se apoia nas interações estabelecidas entre os sujeitos sociais que produzem discursos passíveis de análise e interpretação. Esses discursos produzidos a partir das relações humanas, têm a capacidade de fundamentar a construção dos conhecimentos relativos aos fenômenos que cercam a sociedade.

O 8o Congresso Ibero-Americano em Investigação Qualitativa, realizado no ano de 2019, recebeu diversos trabalhos científicos, na perspectiva da pesquisa qualitativa, que contemplaram diferentes fenômenos sociais. Contou com a participação de pesquisadores de diversas nacionalidades, falantes da língua portuguesa e espanhola. O evento também envolveu a realização de workshops, painéis de discussão e conferências.

Os trabalhos científicos foram relativos às diversas áreas do conhecimento, destacando-se a Educação, Saúde e as Ciências Sociais. Diante disso, essa edição especial buscou reunir os trabalhos científicos sobre os temas relevantes das Ciências Sociais, considerando o contexto interdisciplinar. 
Neste espaço aberto pela Revista Relações Sociais para a publicação de trabalhos científicos resultantes das investigações qualitativas apresentadas no evento, convergem trabalhos pautados em diversas e múltiplas metodologias científicas, mas que aqui se reúnem para testemunhar e contribuir para o desenvolvimento do rigor científico na investigação qualitativa na área das Ciências Sociais.

A diversidade dos temas que se apresentam nesta edição denota a riqueza das investigações das relações sociais. Reúnem-se, aqui, estudos pautados nas questões de cidadania e relações com entes públicos, na construção social da condição de paternidade na adolescência, da situação de periferia e de experiência de peregrinação voluntária e o estudo da construção da identidade de gênero numa sociedade marcada pela identificação sexual binária. Agregam-se a esses, trabalhos que se ancoram no ambiente empresarial para dizer das dinâmicas sociais em condição de liderança no trabalho e para analisar a construção da imagem institucional respaldada em valores caros à sociedade, mas também genéricos, como é o caso da sustentabilidade e do bem-estar social.

No que se refere às metodologias científicas, destacaram-se como técnicas para coleta de dados a história de vida, a entrevista em profundidade e narrativa, o questionário e a análise das mídias sociais, neste caso ressaltando-se o uso de jornais, propagandas institucionais e redes sociais virtuais. Assim, a partir dos artigos selecionados observou-se que os autores buscaram compreender os fenômenos sociais a partir de fontes de informação primárias e secundárias.

Em relação ao tratamento dos dados, verificou-se a utilização das técnicas de análise temática, narrativa, análise do discurso e análise de conteúdo. Os autores destacaram a importância da abordagem metodológica qualitativa para a compreensão de experiências, percepções e significados atribuídos pelos sujeitos para a interpretação dos fenômenos sociais, visando, principalmente, a construção de um conjunto de imagens e discursos interpretativos.

Acredita-se que esta edição especial apresenta forte contributo científico, uma vez que adveio de um esforço conjunto e multidisciplinar de diversos autores na área de investigação qualitativa, considerando-se pertinente a aglutinação e a publicação dos artigos, das análises empíricas e dos estudos teóricos de distintas perspectivas metodológicas.

Foram selecionadas publicações de distintas disciplinas, a fim de que, nesta edição especial, se possa contemplar um vasto cardápio dedicado à investigação qualitativa, com vistas à enriquecer e acrescentar visibilidade crítica à produção e à comunidade acadêmica, levando em consideração a multiplicidade de abordagens metodológicas e a abertura para novas posicionamentos conceptuais, face às circunstâncias e tendências que os novos paradigmas teóricos e metodológicos imputam. 
A alta qualidade dos artigos selecionados e o empenho na difusão científica, para o que a Revista Relações Sociais confere importante contributo, as editoras convidadas se realizaram na desafiadora tarefa que tornou possível a publicação desta edição à luz da transdisciplinaridade estabelecida entre as áreas da Educação, Saúde e das Ciências Sociais. Tal feito somente foi possível diante do apoio de todos que, de uma forma sinergética, aceitaram colaborar enquanto revisores, autores e editores, e que contribuíram para a discussão e o aprofundamento das análises dos fenômenos sociais a partir da abordagem qualitativa.

Na sua essência, esta publicação resulta do acreditar na possibilidade de difundir os percursos metodológicos e os resultados dos estudos apresentados no evento científico em espaço internacional, em particular, nos países Ibero-Americanos que, de forma maciça, contribuíram para a publicação dos artigos que enriquecem o conhecimento e o aprimoramento do metodologia qualitativa na comunidade científica e acadêmica.

\section{Agradecimentos}

As editoras finalizam agradecendo a todos e todas que de alguma forma colaboraram com o CIAIQ2019, e particularmente, aos que se dedicaram diretamente à produção deste número especial, incluindo os participantes, autores, comissão organizadora e científica, apoios, equipe editorial, entre outros. Por meio do interesse e participação dos pesquisadores, e da qualidade e rigor dos trabalhos científicos, agora publicados na Revista Relações Socais, espera-se a investigação qualitativa seja promovida para a compreensão de temas das Ciências Sociais.

\section{Referência}

BOURDIEU, P. A Miséria do Mundo. 4. ed. Petrópolis, RJ: Vozes, 1997. 